\title{
CONSIDERAÇÕES SOBRE A \\ EVOLUÇÃO COMPETITIVA DE \\ EMPRESAS DO PONTO DE VISTA \\ DE FORMAÇÃO DE EQUIPES
}

Maria Lúcia Trezza Bersou e Luiz Bersou

\section{LIDERANÇA E CONSTRUÇÃO DA CULTURA}

Vamos avançar um pouco com nossas ferramentas e trabalhar a relação cultura versus características do líder. Procura-se, assim, criar premissas de orientação ao líder do ponto de vista de construção de uma cultura saudável no âmbito da empresa. Trata-se de um tema delicado, pois envolve o trato emocional dos colaboradores da empresa, o que, sem o devido preparo, pode trazer sofrimento desnecessário às pessoas envolvidas.

Como ferramenta de trabalho introduzimos o conceito de cultura de cristalização e cultura de sedimentação. A cultura de sedimentação pode ser definida como aquela que é derivada do armazenamento proveitoso das experiências vividas pela empresa ao longo de sua existência. $O$ acervo assim constituído permite um estado de relações no qual a energia despendida pelos colaboradores está prioritariamente orientada para o benefício da empresa. O esforço de colaboração de uma equipe assim constituída contribui para o aperfeiçoamento de cada um e da equipe como um todo, a partir de uma situação global de crescimento.

Numa cultura de cristalização, as experiências vividas pela empresa não fertilizam o caminho que ela percorre ao longo de sua história de vida. O que se verifica é que tais experiências apenas se sobrepõem umas às outras, como elementos isolados num conjunto estático, sem referências e sem esquemas dinâmicos de trocas. Nas culturas assim constituídas a energia despendida pelos colaboradores costuma estar mais voltada para os interesses individuais imediatos, em detrimento da atenção dada à empresa, com grande dispêndio de energia tencional e com consequiente efeito paralisante.

\section{CULTURA E EQUIPES}

Uma outra excelente ferramenta conceitual é aquela que diz respeito ao reflexo cultura eficiência de grupo. Com efeito, o que interessa do ponto de vista da empresa é que a cultura vigente transforme grupos de colaboradores em equipes.

Uma equipe pode ser assim identificada quando entre seus membros está presente o conhecimento comum dos problemas e das ferramentas de trabalho, o comprometimento com uma determinada causa, projeto ou problema e a preocupação com a construção de um determinado ambiente de trabalho.

Assim, ao arquiteto do plano de desenvolvimento do ambiente interno da empresa cabe a missão de criar condições para a construção de uma cultura de sedimentação, mais saudável e mais fértil. Dentro dessa tarefa impõe-se, portanto, transformar grupos em equipes, propiciando condições para que exista compartilhamento dos problemas, o domínio de ferramentas de trabalho comuns, a formação de um ambiente de trabalho pró-ativo e o estabelecimento de um grau de comprometimento necessário para alcançar os objetivos estabelecidos. Com este quadro teremos equipes mais engajadas e, portanto, mais eficientes.

\section{CRIAÇĀO DA CULTURA DE SEDIMENTAÇÃO}

A criação da cultura de sedimentação está baseada em um conjunto de pressupostos fundamentais e que estão na base das equipes competentes.

Nas relações de trabalho do dia-adia, procuram-se mais as causas dos 
problemas e menos os culpados. Essa premissa é de fundamental importância na formação do ambiente de trabalho no qual deverão se estabelecer as relações funcionais.

A abordagem dos problemas é preferencialmente feita no âmbito do "pensar junto" ao invés de "pensar contra". A situação de "pensar junto" não implica necessariamente estar de acordo, mas estabelece as bases para o conhecimento comum do problema e fixa a identificação entre as partes das ferramentas de pensar, elemento fundamental na formação de uma equipe.

Os objetivos e contratos individuais de trabalho são sempre bem estabelecidos. Desta situação decorrem relações de trabalho mais transparentes e maduras. Ficando claros os deveres e responsabilidades de cada um, é possível cobrar adequadamente os resultados esperados.

Ainda quando rigorosas, as relações de trabalho merecem trato afetuoso, motivação, reconhecimento e a busca do entendimento das necessidades de cada um. Ambientes de cordialidade e de reconhecimento são elementos fundamentais na construção de equipes. Os líderes que conseguem estabelecer relações afetuosas e reconhecidas com seus colaboradores têm verdadeiras equipes, altamente identificadas com seus propósitos e com a empresa. Líderes que não conseguem essa condição coordenam na verdade equipes mancas, desmotivadas e que, com freqüência, na procura de atender necessidades próprias, drenam energia vital para fora da empresa.

As críticas são equilibradas, profissionais, justas e acima de tudo apresentadas com respeito entre as partes. Esta é a ferramenta de sustentação da cultura de sedimentação. Nesta condição as equipes não receiam em apresentar suas próprias convicções e contribuições, e o fator de alavancagem da equipe aumenta consideravelmente.

O trabalho desenvolvido em culturas cristalizadas apresenta algumas características específicas no âmbito das equipes: são equipes viciadas em se defender, mesmo diante de contribuições úteis, anestesiadas quanto às criticas que recebem, sem compromisso com a resposta e também impermeáveis a qualquer processo de evolução. São equipes muito resistentes, de difícil penetração, neutralizando as iniciativas que possam resultar em mudanças, as quais são vividas como ameaça ao precário equilíbrio que as mantêm.
Quando construímos equipes com cultura sedimentada, percebemos imediatamente que são equipes sensíveis, com grande carga de amor-próprio, atuam colaborando e não defensivamente, levam seriamente as críticas que recebem, sentem-se comprometida com a resposta e têm brio profissional. Tais equipes só podem florescer num ambiente propício: estimulante, sadio, transparente, inteligente, que respeite sua sensibilidade e amor próprio.

Meses de trabalho podem ser perdidos pela falta de percepção de que, quando fazemos uma cultura de cristalização evoluir para uma cultura de sedimentação, estamos refazendo a história do cavalo árabe puro sangue: excepcional performance exige condições excepcionais de ambiente e vivência.

\section{CORRELAÇĀO ENTRE CULTURAS DE SEDIMENTAÇÃO, FORMAÇĀO DE EQUIPES E TIPOS DE LIDERANÇAS}

Examinados os pressupostos da formação da cultura de sedimentação e formação de equipes, cumpre examinar os aspectos de liderança que se apresentam diante destes pressupostos.

Tradicionalmente, a formação de empresas com origem industrial estabeleceu pressupostos de exercício de liderança baseados essencialmente em argumentos racionais. Este processo funcionou por muito tempo, enquanto a questão de tocar uma empresa do ponto de vista de fabricação era um tema técnico, de soluções técnicas e poucas dúvidas quanto a outras necessidades.

Como a exigência quanto ao melhor aproveitamento de recursos humanos era muito pobre, a questão da importância desse recurso no contexto da organização era deixada de lado. Com o aumento da complexidade da empresa, percebeu-se que $o$ argumento "equipe" era mais importante do que o argumento "máquina" e a partir daí passos importantes foram dados na busca da otimização da condição competitiva da empresa via otimização do uso dos recursos pessoais das equipes.

Nesta condição evidencia-se que os pressupostos básicos de liderança, ainda que não possam prescindir da lógica racional, devem compor-se com argumentos emocionais. $\mathrm{O}$ exercício da moderna condução de empresas está baseado no binômio "argumentos racionais" mediados por "argumentos emocionais".

O que sabemos deste binômio? Que ele é 


\section{Tendências}

fundamental para a formação de verdadeiras equipes.

Quando o binômio se desloca para o racional, prevalece a cultura de cristalização pela falta de empatia do líder com seus liderados. $\mathrm{O}$ grupo até pode ser competente, mas o ambiente será frio e pouco produtivo. Teremos líderes autocráticos e ineficientes.

Quando o binômio se desloca para o emocional, também se estabelece uma cultura de cristalização, como é típico no caso dos partidos políticos. Temos um ambiente extremamente emocional, porém pouco competente. Temos então líderes pseudo-democráticos e igualmente ineficientes.

Quando o binômio funciona de maneira equilibrada, o emocional temperando o racional na justa medida, os líderes terão condições de conquistar o verdadeiro reconhecimento e a fidelidade de sua equipe.

Diante dessa análise cabe perguntar como se posicionam os líderes em relação a este binômio. $\mathrm{O}$ equilíbrio ideal do líder diante desses dois aspectos está diretamente relacionado com o equilíbrio interno próprio de cada indivíduo. Essa equação é definida pelo grau de contato que o líder é capaz de operar entre seus aspectos emocionais e suas capacidades intelectuais.

Quando essas duas áreas no líder estão demasiado estanques, a comunicação indispensável entre os fatores emocionais e as habilidades intelectuais fica comprometida. Isso o impede de compreender a situação como um todo e de poder ajudar com seus conhecimentos e experiência, bloqueando a integração entre líder e equipe. Esta questão é de suma gravidade, pois ela atinge todas as escalas de liderança de uma empresa. Vai do presidente até o último dos colaboradores que, por uma razão ou outra, exerce momentos de liderança e comando.

Nos casos em que os argumentos racionais e emocionais transitam mais livremente, teremos líderes capazes de galvanizar suas equipes. Nos casos em que há um fosso entre as esferas racionais e emocionais, os argumentos não transitam e instalam-se problemas.

Tradicionalmente, os líderes industriais e os militares estão muito mais habituados a utilizar argumentos racionais. Por outro lado, os líderes políticos em geral atuam no âmbito inverso, valendo-se predominantemente da argumentação emocional. Claramente, o extremo dos dois casos configuram situações de grande risco para as entidades envolvidas, levando empresas à morte e nações à guerra.

\section{REFLEXOS DA CULTURA NA CONDIÇĀO COMPETITIVA DA EMPRESA}

Já sabemos como se reflete a condição operacional do líder na cultura da empresa. Precisamos saber agora como a caracterização da cultura de sedimentação se reflete na condição competitiva da empresa e, portanto, no risco que ela enfrenta no dia-a-dia. Este problema pode ser abordado a partir dos seguintes enfoques:

a) comunicação com o mercado: como nas empresas com cultura de sedimentação quase não existem tabus e verdades absolutas, a absorção de dados e valores de mercado pelo ambiente interno da empresa é muito mais frequiente e, o que é mais importante, muito mais valorizada. Em decorrência disto, poderíamos afirmar que as culturas de sedimentação revelam maior sintonia com o mercado. Por outro lado, nas culturas de cristalização predomina uma resposta mais mecânica e estereotipada, o que impossibilita a necessária sintonia em relação à dinâmica do mercado;

b) evolução da curva de maturidade da empresa: esta abordagem de análise é igualmente muito importante e se completa com a anterior. A cultura de cristalização na empresa faz com que sua curva de maturação fique bloqueada em patamares nitidamente distintos. Normalmente, a cultura de cristalização. atrasa a evolução dos patamares de amadurecimento da empresa.

\section{EVOLUÇÃO DO TRATAMENTO DO RISCO EXTERNO E INTERNO NA EMPRESA E CULTURA DE SEDIMENTAÇĀO}

Os conceitos de "risco interno" e "risco externo" têm o objetivo fundamental de caracterizar as importâncias relativas dos dois tipos de risco, caracterizando-os adequadamente para cada negócio específico e estabelecendo a relação empresa versus tratamento do risco interno e externo. Os gráficos a seguir propõem uma noção de como pode ser a posição da empresa e o objetivo de trabalho conjunto entre empresa e consultoria.

A partir daí é possível concluir que a cultura de cristalização afeta a empresa de várias maneiras: 
CONSIDERAÇOES SOBRF A EVOLUCÄO COMPETITIVA DE EMPRESAS...

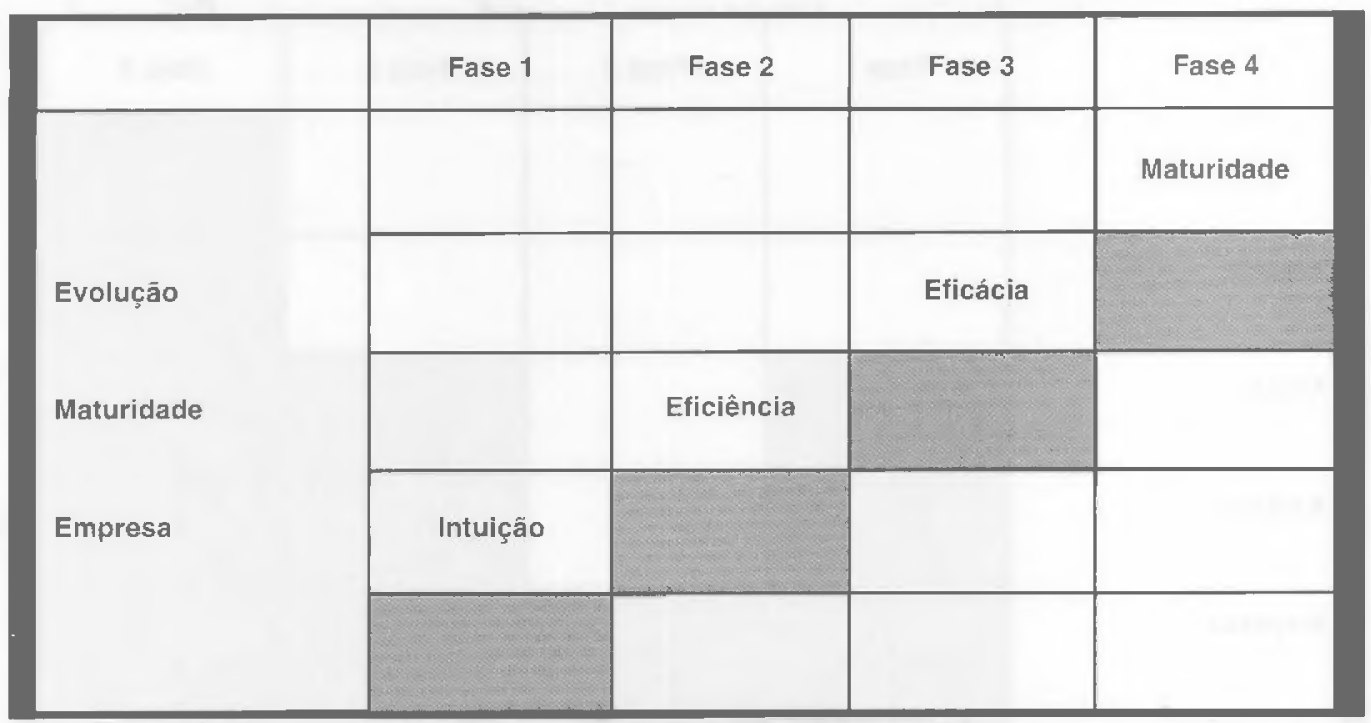

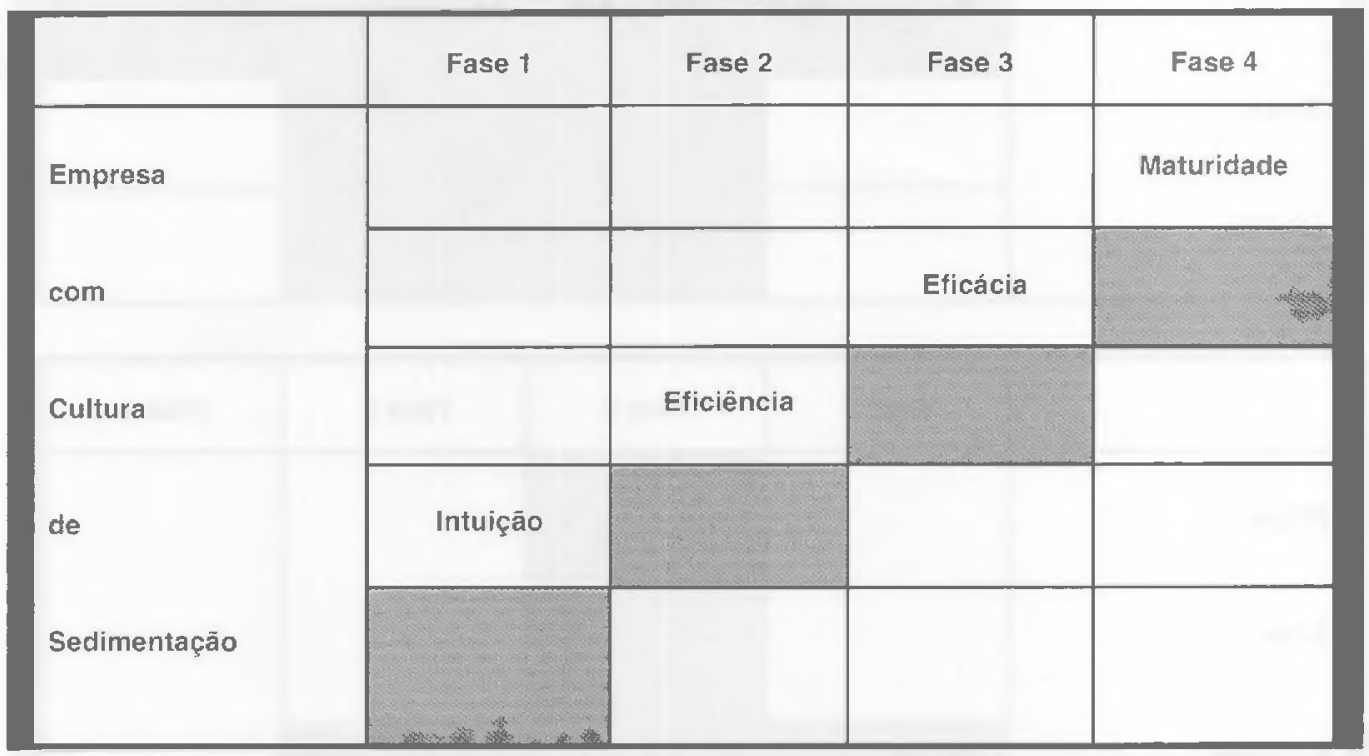

\begin{tabular}{|c|c|c|c|c|}
\hline & Fase 1 & Fase 2 & Fase 3 & Fase 4 \\
\hline Empresa & & & & \\
\hline com & & & Eficácia & \\
\hline Cultura & & Eficiência & & \\
\hline de & Intuição & & & \\
\hline Cristalização & & & & \\
\hline
\end{tabular}




\begin{tabular}{|c|c|c|c|c|}
\hline & Fase 1 & Fase 2 & Fase 3 & Fase 4 \\
\hline \multicolumn{5}{|c|}{ Atenção } \\
\hline \multicolumn{5}{|l|}{ Risco } \\
\hline \multicolumn{5}{|l|}{ Externo } \\
\hline \multicolumn{5}{|c|}{ Empresa } \\
\hline \multicolumn{5}{|c|}{ Atenção } \\
\hline \multicolumn{5}{|l|}{ Risco } \\
\hline Interno & & & & \\
\hline
\end{tabular}

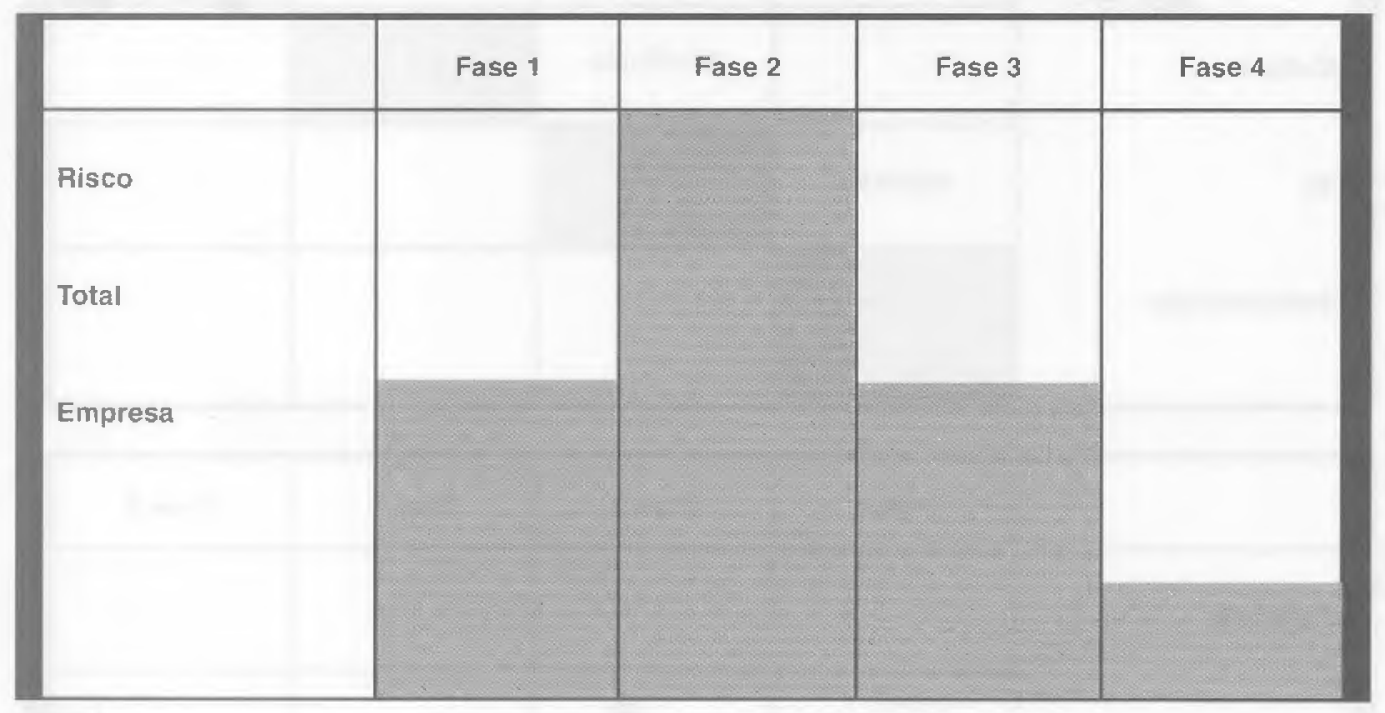

a) năo permite que a empresa atinja um optimum de condição competitiva, uma vez que as empresas com cultura de cristalização, por sua própria natureza, estão impedidas de atingir a fase de maturidade, que é aquela em que o risco da empresa é menur;

b) dado que o nível de conforto interno da empresa é escasso, a rotação de quadros com a conseqüiente perda de competência ganha maior relevância; c) além disso, empresas com cultura cristalizada geram menos conhecimento.

O resultado final é que empresas com cultura cristalizada apresentam sempre maior risco de mercado. $\square$

Maria Lúcia Trezza Bersou e Luiz Bersou são consultores da BCA Consultoria Empresarial. 